\title{
Studying physico-mechanical properties of cement pastes in presences of blend polymer as chemical admixtures
}

\author{
Negim E.S.M ${ }^{1,2}$ *, Yeligbayeva G.Zh. ${ }^{3}$, Niyazbekova R. ${ }^{4}$, Rakhmetullayeva R. ${ }^{5}$, \\ Mamutova A.A. ${ }^{5}$, Iskakov R. ${ }^{1}$, Sakhy M. ${ }^{6}$, Mun G.A. ${ }^{5}$ \\ ${ }^{1}$ School of Chemical Engineering, Kazakh-British Technical University, 106 Walikhanov Street, Almaty, 050010, Kazakhstan \\ ${ }^{2}$ National Research Centre, Polymer \& Pigment Department, 33 El Bohouth St., Dokki, Giza, 12622, Egypt \\ ${ }^{3}$ K.I. Satpaev Kazakh National Technical University, 22 Satpaevavenue, Almaty, 050013, Kazakhstan \\ ${ }^{4}$ Faculty of Transport and Energy of the L.N. Gumilyov Eurasian National University, Astana, kazakhstan \\ ${ }^{5}$ Al-Faraby Kazakh National University, 050038 Almaty, Kazakhstan \\ ${ }^{6}$ Taraz State University named after M.H. Dulati, 60 Tole Bi Street, O80000Taraz, Kazakhstan \\ *Corresponding authorE-mail: elashmawi5@yahoo.com
}

Copyright $\odot 2015$ Negim E.S.M et al. This is an open access article distributed under the Creative Commons Attribution License, which permits unrestricted use, distribution, and reproduction in any medium, provided the original work is properly cited.

\begin{abstract}
Physico-mechanical properties of cement pastes were studied by setting time, combined water, compressive strength, SEM as well as porosity in presence of blend polymers. Blend polymers were used based on polyvinyl alcohol and carbamide with blend ratios 20/80, 40/60 and 80/20 respectively. The addition of blend polymers to cement pastes affected the physico-mechanical properties of cement pastes. As the content of carbamide in the polymer blends decreased, the water of consistency decreased, whereas the setting times (initial \& final) were elongated. The combined water content and compressive strength of the hardened cement pastes were increased at all ages of hydration. The SEM images showed that the addition of these polymers to cement material improves the dispensability and workability of cement pastes.
\end{abstract}

\section{Introduction}

Chemical admixtures are natural or manufactured chemicals, which are added to the concrete or mortar containing water, aggregates and hydraulic cement before or during mixing to improve the properties of concrete [1]. Meishanet al, [2] synthesized water-soluble sulfonated acetone-formaldehyde (SAF) polymer from acetone, formaldehyde and sodium bisulfate. The product was used as chemical admixture in concrete. The result shown that the molecular weight (MW) of SAF is a major factor to improve specific properties of concrete such as workability, compressive strength and slump loss control. Zhang et al., [3] synthesized a starch succinate half ester material (SSHE) used as the water-reducing agent. The effects of both dosage of SSHE and storing time on the fluidity of cement paste were evaluated in comparison with that of carboxymethyl starch (CMS) dispersion ability. Results show that the SSHE is a new type of water-reducing agent with super retarding effect. This is mainly because of the dispersion capacity of SSHE comes from steric repulsion and the effect of super retarding results from reactive succinate half ester groups in acid form. Negim et al., [4-6] prepared copolymer poly [acrylic acid-co-styrene] and poly [2-hydroxy ethyl acrylate-co-vinyl ether of ethylene glycol] by solution polymerization using azo-bis-isobutyro-nitrile (ABIN) as an initiator and ethanol as a solvent. The performance of copolymers on the physical and mechanical properties of Portland cement (PC) pastes was investigated. The results showed that the copolymer improves most of the specific characteristics of PC as decreased the W/C ratio, retarded of the setting time (initial and final), and increased the combined water content and compressive strength. Ayoub et al., [7] and Negim et al., [6] synthesized a series of graft polymer polyvinyl acetate-gpolyoxyethylenemonomethylether (MPOE-g-PVAc) and another series of methoxypolyoxyethlene-g-poly maleic anhydride (MPOE-g-PMA) The graft polymers have applied to investigate the effect of graft polymer on specific 
characteristics of ordinary Portland cement (PC); results indicate that the grafted polymer improves the major properties of $\mathrm{PC}$ as $\mathrm{W} / \mathrm{C}$ ratio, setting time and compressive strength.

The present work was designed to study the effect of polyvinyl alcohol/carbamide blends on the physico-mechanical properties of cement pastes as chemical admixture.

\section{Experiments}

\subsection{Materials}

Polyvinyl alcohol (PVA) of molecular weight 14 x $103 \mathrm{~g} / \mathrm{mol}$ purchased from Merck (Germany). Carbamide (C), glacial acetic acid and methanol were purchased from Aldrich and used without purification.

The raw materials used in the present study are Portland cement clinker (PCC) and raw gypsum (G). Each of these raw material was separately ground in a steel ball mill until the surface area of 3650 and $2800 \mathrm{~cm}^{2} / \mathrm{g}$ [8] respectively, were achieved. The chemical composition of the raw materials is shown in Table 1. The mineralogical composition of the PCC sample is $\mathrm{C}_{3} \mathrm{~S}, 58.79 \% ; \beta-\mathrm{C}_{2} \mathrm{~S}, 17.68 \% ; \mathrm{C}_{3} \mathrm{~A}, 8.08 \% ; \mathrm{C}_{4} \mathrm{AF}, 9.72 \%$. The ordinary Portland cement was prepared by mixing 96 wt. \% PCC and 4 wt. \% G in a porcelain ball mill for one hour using three balls to sure complete homogeneity of the cement. The Blaine surface area of the cement sample was $3350 \mathrm{~cm}^{2} / \mathrm{g}$.

Table 1: The Chemical Composition of the Raw Materials, Mass \%.

\begin{tabular}{llllllllll}
\hline Oxides Materials & $\mathrm{SiO}_{2}$ & $\mathrm{Al}_{2} \mathrm{O}_{3}$ & $\mathrm{Fe}_{2} \mathrm{O}_{3}$ & $\mathrm{CaO}$ & $\mathrm{MgO}$ & $\mathrm{SO}_{3}$ & $\mathrm{Na}_{2} \mathrm{O}$ & $\mathrm{K}_{2} \mathrm{O}$ & $\mathrm{L} . \mathrm{O} . \mathrm{I}$ \\
\hline $\mathrm{PCC}$ & 21.48 & 6.03 & 4.22 & 64.29 & 0.68 & 0.39 & 0.21 & 0.11 & 2.59 \\
$\mathrm{G}$ & 0.58 & 0.14 & 0.11 & 30.08 & 0.13 & 45.36 & 0.07 & 0.09 & 23.44 \\
\hline
\end{tabular}

$\mathrm{PCC}=$ Portland cement clinker, $\mathrm{G}=$ gypsum, L.O.I $=$ Loss on ignition

\subsection{Preparation of the blend films}

PVA/C blends with different blend ratios 20/80, 40/60 and 80/20 respectively were prepared. Briefly, PVA and carbamide $(\mathrm{C})$ were dissolved in distilled water in a three necked flask under continuous mechanical stirring and heating in a water bath at $90 \pm 3{ }^{\circ} \mathrm{C}$ for 20 min till complete dissolution of PVA and C, and then, the flask was sealed with a septum stopper. The prepared solution was flushed with Nitrogen gas, which was introduced through a hypodermic needle, and another needle was introduced inside the stopper for the outlet of Nitrogen gas. Glacial acetic acid was injected through a hypodermic needle during preparation in order to control the $\mathrm{pH}$ of the solution at $3 \pm 1$. Nitrogen gas flushing was continued for a further $30 \mathrm{~min}$ and then stopped. The needles were removed from the stopper, and then the flask was sealed with a Teflon tape. The temperature of the reaction was maintained at $90 \pm 3^{\circ} \mathrm{C}$ for another three hours.

\subsection{Mixing and test}

The prepared copolymer was added to water and then added gradually to $300 \mathrm{~g}$ of the dry cement in order to determine the water of consistency and setting time using Vicat apparatus [9], [10]. The determined water of consistency premixed with the copolymer was added to $500 \mathrm{~g}$ of the dry cement. The resulting cement pastes were directly moulded into oneinch cube stainless steel moulds. The moulds were manually agitated for 2 minutes and then on a vibrator for another 2 minutes for complete removal of air bubbles and voids and to produce suitable pastes. The moulds were kept in a humidity chamber at $100 \%$ and at constant room temperature overnight, then demoulded and cured under water till the time of testing (1, 3, 7 and 28 days) for total porosity and compressive strength (ASTM, C170-90, Standards, 1993).The compressive strength was carried out using a hydraulic testing machine of Type LPM 600 M1 SEIDNER (Germany) having full capacity of $600 \mathrm{KN}$. The loading was applied perpendicular to the direction of the upper surface of the cubes. The total porosity, $\xi$ of each sample at any interval was calculated from the following equation [12]:

$\xi=0.99 \times \mathrm{We} \times \mathrm{dp} /(1+\mathrm{Wt})$

Where 0.99 is the specific volume of the free water, We is the evaporable water content; dp is the bulk density; $\mathrm{g} / \mathrm{cm} 3$ and $\mathrm{Wt}$ is the total water content which is equal to the sum of evaporable water (We) and combined water (Wn) contents. The bulk density $(\mathrm{dp})$ was determined from the following equation: $\mathrm{dp}=\mathrm{W}_{1} / \mathrm{W}_{1}-\mathrm{W}_{2} \mathrm{~g} / \mathrm{cm}^{3}$, where $\mathrm{W}_{1}$ is the saturated surface dry weight in air $(\mathrm{g})$ and $\mathrm{W}_{2}$ is the submerged weight in water $(\mathrm{g})$. To stop the hydration at any age of hydration, a representative sample of about $10 \mathrm{~g}$ after the determination of compressive strength was taken, ground in an alumina mortar containing $50 \mathrm{~mL}$ of 1:1 (methanol: acetone) solution mixture and then filtered through a sintered glass funnel (G4). The sample was washed with $50 \mathrm{~mL}$ fresh diethyl ether, dried at $70{ }^{\circ} \mathrm{C}$ for one hour and then kept inside an airtight bottle as described elsewhere [11]. The curing water was renewed every week. The combined water content (Wn) of samples predried at $105^{\circ} \mathrm{C}$ for 24 hours was determined as the ignition loss at $1000{ }^{\circ} \mathrm{C}$ for 30 minutes [1]. The microstructure of the hydrated cement pastes was investigated by scanning electron microscopy (SEM) and elemental analysis. The SEM images of the 7-days hydrated cement pastes was used for the Microanalysis INCA 
(Oxford instrument-UK), combined with scanning electron microscope Super prob. 733-Joel (Japan). For this purpose, the samples were coated by a thin layer of gold palladium to be electrically conductive and to increase its contrast of display.

\section{Results and discussion}

\subsection{Water of consistency and setting time}

Generally, the water/cement (W/C) ratio for the various cement pastes has an important influence on the quality of concrete produced. The cement-water system is highly sensitive to the addition of chemical admixture. Already small amounts of chemical admixtures enhance the workability properties efficiently, but are often associated with strong, undesired retardation phenomena of the setting of the cement paste. The results of water consistency as well as setting time of the various cement pastes mixed with different dosage of PVA/C blends are shown in Table 2. It is clear that the W/C ratio of cement pastes decreases from 0.28 to 0.273 with addition of the polymer blends and then become constant even with increasing concentration of the polymer blends. In a general sense, chemical admixtures are often used as water reducers, to make concrete stronger by lowering the water/cement ratio [13].

Table 2: The Effect of Concentration of PVA/Cblends on the Setting Time and W/C Ratio of PC Paste

\begin{tabular}{|c|c|c|c|c|}
\hline \multirow{2}{*}{ Polymer } & \multirow{2}{*}{$\begin{array}{l}\text { Concentration of polymer } \\
\%\end{array}$} & \multirow{2}{*}{$\mathrm{W} / \mathrm{C}$ ratio } & \multicolumn{2}{|c|}{ Setting time, min. } \\
\hline & & & Initial & Final \\
\hline ---------- & --------- & 0.28 & 150 & 360 \\
\hline \multirow{3}{*}{$\begin{array}{l}\text { PVA/C } \\
(20 / 80)\end{array}$} & 0.25 & 0.26 & 158 & 370 \\
\hline & 0.50 & 0.26 & 178 & 432 \\
\hline & 1.00 & 0.26 & 205 & 541 \\
\hline \multirow{3}{*}{$\begin{array}{l}\mathrm{PVA} / \mathrm{C} \\
(40 / 60)\end{array}$} & 0.25 & 0.265 & 160 & 430 \\
\hline & 0.50 & 0.265 & 192 & 455 \\
\hline & 1.00 & 0.265 & 210 & 559 \\
\hline \multirow{3}{*}{$\begin{array}{l}\text { PVA/C } \\
(80 / 20)\end{array}$} & 0.25 & 0.273 & 215 & 466 \\
\hline & 0.50 & 0.273 & 225 & 474 \\
\hline & 1.00 & 0.273 & 230 & 605 \\
\hline
\end{tabular}

Amount of OPC is fixed $=300 \mathrm{gm}$

$\mathrm{W} / \mathrm{C}$ ratio $=$ weight of water/weight of cement

The setting time (initial \& final) of pastes studied are given in Table 2, which shows that as the dosage of the (PVA/C) increases, setting times lengthen. This is mainly due to the water loss by evaporation from the outer surfaces of the specimen mixed with the polymer blends are relatively less than that of cement pastes. Furthermore, there may be a relationship between the type of polymers and the elasticity of the cement pastes [14]. On the other hand, the setting time of the cement pastes increased with increasing ratios of PVA in the prepared polymer blends. The delay of setting is thought to relate to the concentration of amide groups in the aqueous phase. The setting time of cement paste depended roughly on the ionic functional group concentration in the aqueous phase of the cement paste [15].

\subsection{Chemically combined water content}

It is estimated that the chemically combined water content is an evidence of the quantitative increase of the new hydration products that formed in the hardened cement pastes during hydration process [16], [17]. The combined water contents of the cement pastes premixed with freshly polymer blends are graphically plotted as a function of curing time in Figure 1. The results show that the combined water content of all samples increased with the increase in curing time. It is attributed to the cement hydration process generally precedes the polymer film formation process by the coalescence of polymer particles in polymer blends. It is very important that both cement hydration and polymer film formation proceeds well to yield a monolithic matrix phase with a network structure in which the cement hydrate phase and polymer phase interpenetrate. The film forming process in the pore solution of cementitious materials can be ascribed to the influence of the altered conditions on the drying rate of the polymer dispersion. In addition, owing to cement hydration, additional forces may be exerted on the water of the polymer particles. Extra water withdrawal results in more closely packed polymer particles, and coalescence can take place at even lower temperatures [18].

Furthermore, the combined water content of the cement pastes premixed with the polymer blends increases with the increase in the ratios of PVA in the polymer blends. It in proved that and that as admixture having a functional group (amid group) producing a complex salt with $\mathrm{Ca}^{2+}$ decrease the concentration of $\mathrm{Ca}^{2+}$ in liquid phase at early age and delays the saturation of $\mathrm{Ca}^{2+}$, which influences the morphology of hydrate produced [19]. 


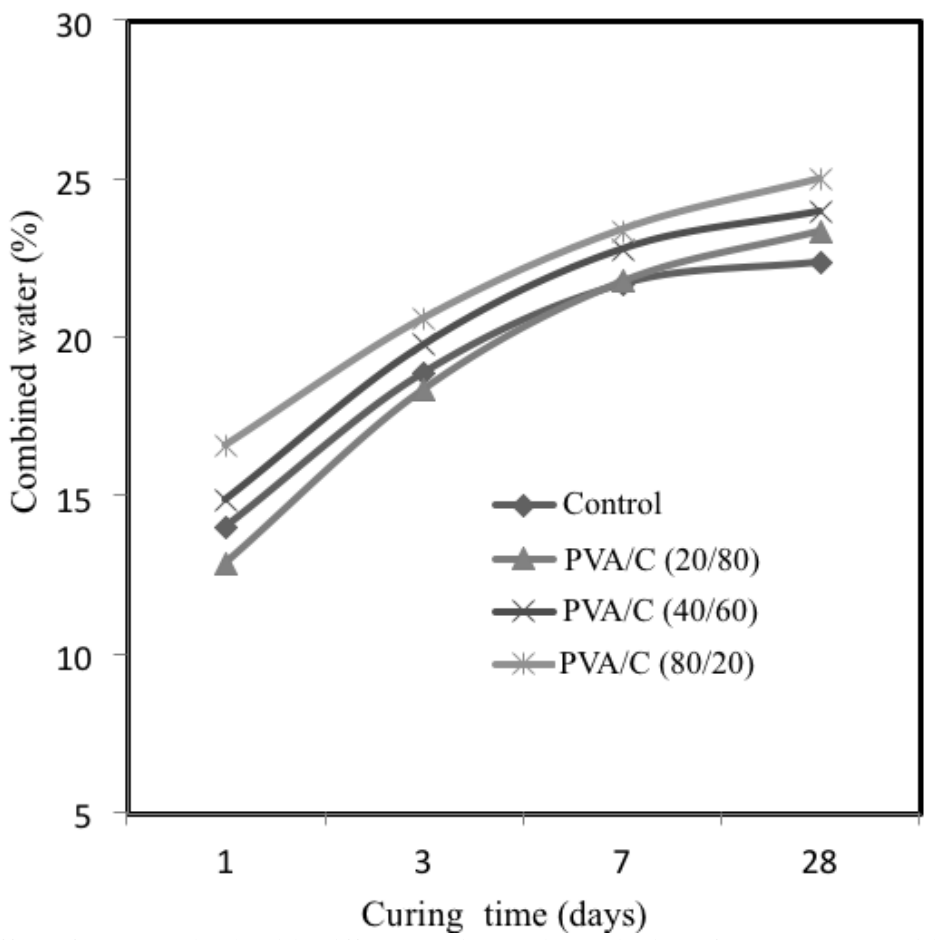

Fig. 1: The Effect of PVA/C Blends with Different Ratios on the Hydration of Cement Pastes with Curing Time

\subsection{Total porosity of the ordinary Portland cement}

The total porosity of the PC pastes mixed with different ratios and concentrations of (PVA/C) blends are plotted as a function of curing time as shown in Figure 2. The results of total porosity of the cement pastes mixed with PVA/C blends decreased with the increase of PVA in the polymer. This is attributed to the hydration process-taking place and formed hydrated cement that directly deposited into the pore structure of the hardened cement pastes [20].

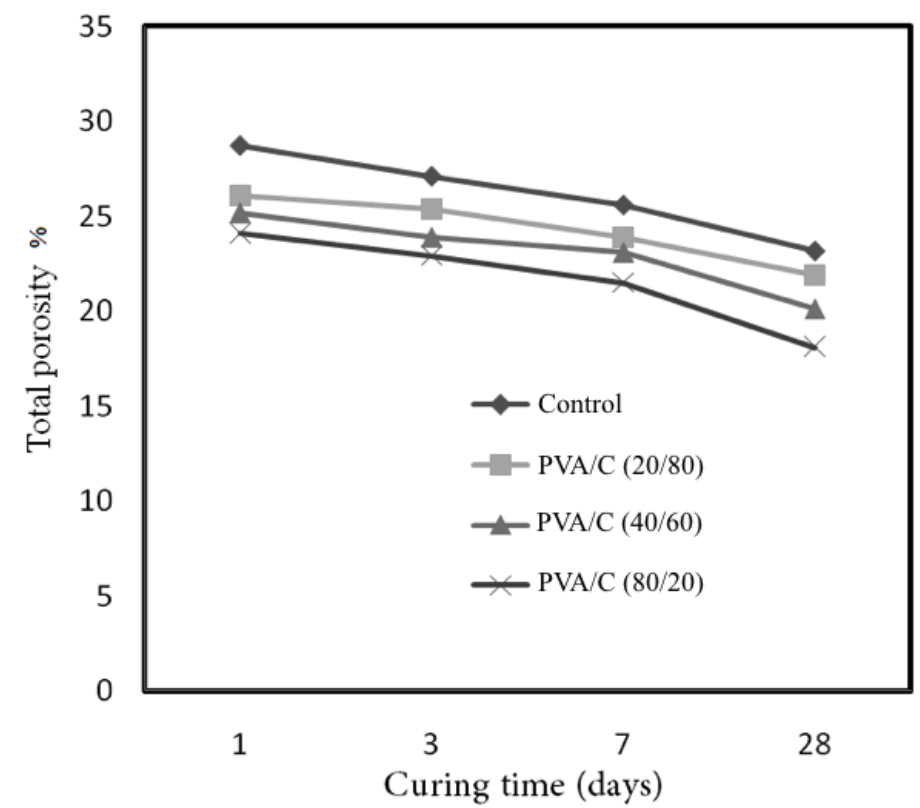

Fig. 2: The Effect of PVA/C Blends with Different Ratios on Total Porosity of the Cement Pastes with Curing Time.

\subsection{Compressive strength}

The compressive strength of PC mixed with different ratio and concentration of (PVA/C) blends was shown to increase with the increasing age of curing as represented in Figure 3. The result also showed that the compressive strength of PC mixed with a different ratio of $(\mathrm{PVA} / \mathrm{C})$ blends is higher than that of the pure cement. Furthermore, the compressive strength of the cement pastes premixed with the PVA/C solutions increased sharply with increasing ratios of PVA in the prepared polymer blends. This is attributed to the continuous formation of the hydration products in the pore structure 
of the hardened cement pastes, which increase the process of polymerization [21]. The growth of crystalline structure leads to the strength development and thus, improve the properties of the cement pastes, the higher degree of polymerization between the particles of cement, will lead to higher compressive strength [22].

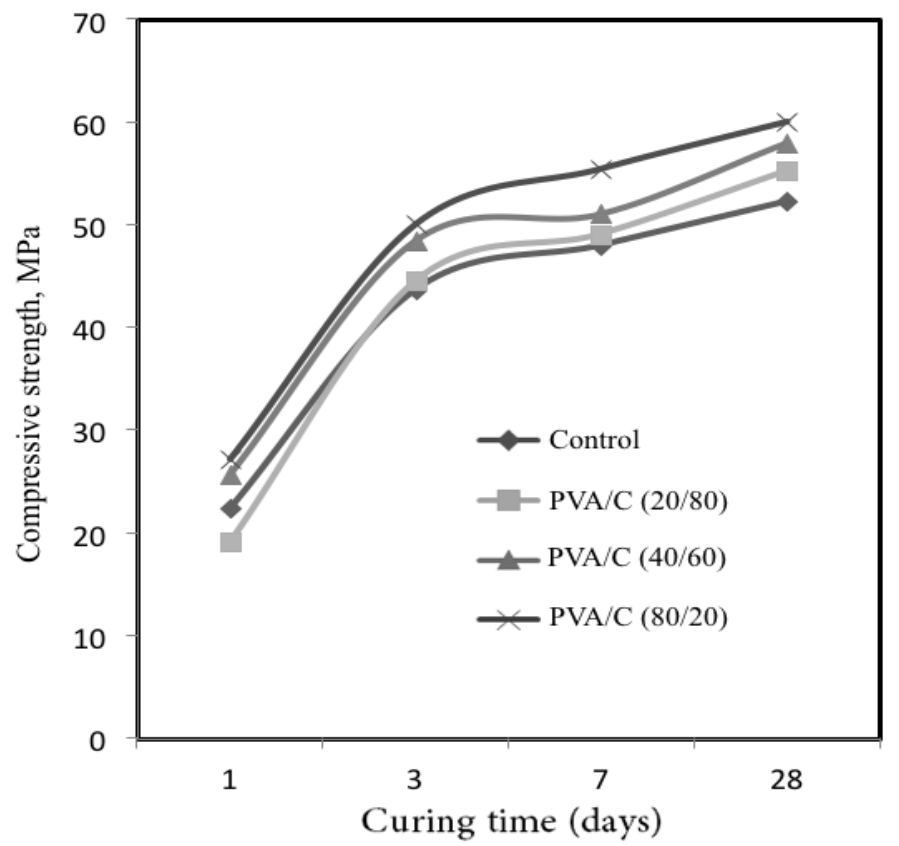

Fig. 3: The Effect of PVA/Cblends with Different Ratios on Compressive Strength of Cement Pastes with Curing Time

\subsection{Scanning electron microscopy}

The scanning electron microscopy (SEM) images of the cement pastes and those premixed with PVA/C blend are shown in Figure 4. Generally, the needles of ettringite phase $\left(\mathrm{C}_{3} \mathrm{~A} .3 \mathrm{CaSO}_{4} \cdot 32 \mathrm{H}_{2} \mathrm{O}\right)$, which were formed due to the reaction of $\mathrm{C}_{3} \mathrm{~A}$ with gypsum in the presence of water, were clearly demonstrated for OPC [23]. These needles decreased or mostly disappeared in presence of the blend polymers. This can be ascribed to the possible whether to the conversion of ettringite to monosulphate $\left(\mathrm{C}_{3} \mathrm{~A} \cdot \mathrm{CaSO}_{4} \cdot 12 \mathrm{H}_{2} \mathrm{O}\right)$ or to the fact that the hydration products were surrounded with the polymer films, which prevented their growth [24], [25]. These observations indicated better hydration of the pastes in the presence of PVA/C blend.

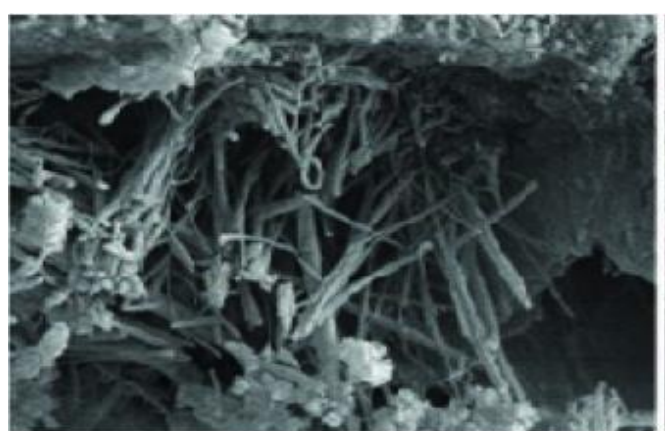

Cement paste

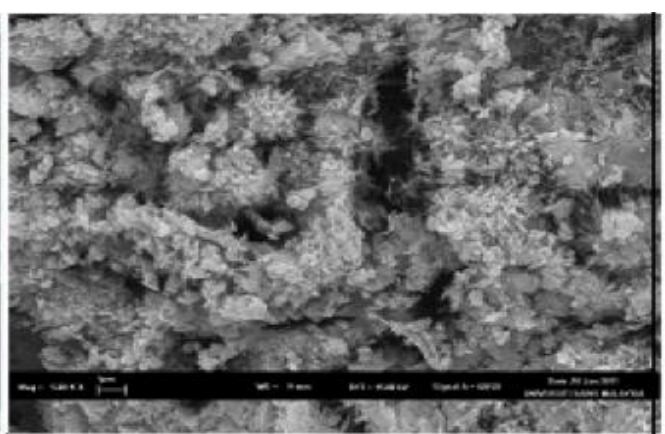

PVA/C (20/80)

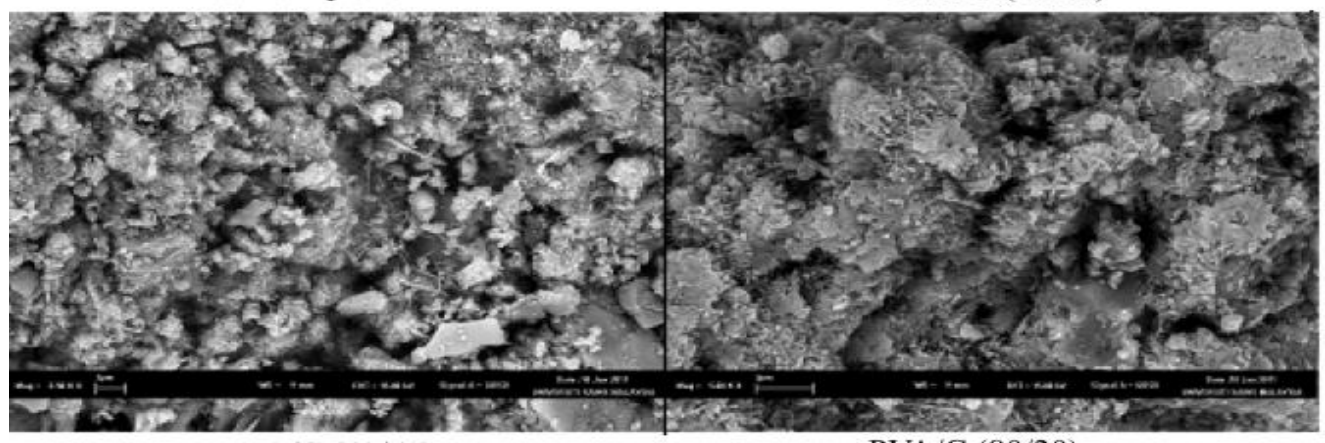

PVA/C (40/60)

$\mathrm{PVA} / \mathrm{C}(80 / 20)$

Fig. 4: The SEM Micrographs of the Pure Cement Paste and Pastes Premixed with PVA/C Blends Hydrated Up to 7 Days. 


\section{Conclusion}

Polymer blends of polyvinyl alcohol (PVA) with carbamide (C) in three different ratios; of 20/80, 40/60 and 80/20 were prepared in aqueous solution, using glacial acetic acid as crosslinking. Mixing of Portland cement powder with water that was premixed with the PVA/C blends evidently improves most of the specific characteristics of the cement pastes. The W/ C-ratio decreases, i.e., the blend polymer acts as a water reducing agent when mixed with the cement powder. The chemically combined water content also enhances and seems to be higher than that of the pure Portland cement pastes at nearly all-curing ages. Their total porosity of the hardened cement pastes premixed with the blend polymers decreased, while compressive strength increased sharply compared with those of the pure hardened cement pastes. As the ratio of PVA in the blend polymer increased, the properties of the cement pastes also improved. The SEM micrographs of adduct polymer mixed with cement hydrated up to seven days showed that the dispersability of cement particles is different from each other and a coarse coagulated structure consisting of various-sized flocks of cement particles is formed with cement pastes premixed with adduct polymers.

\section{References}

[1] Hewlett, P.C., \& Lea's, (1998).Chemistry of Cement and Concrete, $4^{\text {th }}$ John Wiley \& Sons Inc (Ed). New York, Toronto.

[2] Meishan, P., Dujin, W., Xianbo, H., \&Duanfu, X., (2000).Cement \& Concrete Research, 30, 1841. http://dx.doi.org/10.1016/S00088846(00)00389-6.

[3] Zhang, D. F., Ju, B. Z., Zhang, S. F., \& Yang, J. Z. (2008). Carbohydrate Polymers, 71, 80. http://dx.doi.org/10.1016/j.carbpol.2007.05.020.

[4] El-Sayed, M. N., Mahyuddin, R., Saber, E. M., Bahruddin, S., \& Muhammad, I. S. (2010).Middle-East Journal of Scientific Research, 6, 99.

[5] El-Sayed, M. N., Mahyuddin, R., Saber, E. M., Bahruddin, S., \& Muhammad, I. S. (2010).World Applied Sciences Journal, $10,685$.

[6] El-Sayed, M. N., Mahyuddin, R., Saber, E. M., Bahruddin, S., \& Muhammad, I. S. (2010). World Applied Sciences Journal, $10,443$.

[7] Ayoub, M. M. H., Nasr, H. E., Negim, S. M., \&Darweesh, H. H. M. (2005).Polymer-Plastics Technology \& Engineering, 44, 305. http://dx.doi.org/10.1081/PTE-200046097.

[8] ASTM, C204-82, Standards. (1993), Standard test method for fineness of Portland cement by Air permeability apparatus

[9] ASTM, C187-86, Standards. (1993). Standard test method for normal consistency of hydraulic cement, 148

[10] ASTM, C191-92, Standards. (1993). Standard test method for setting time of hydraulic cement by Vicat apparatus, 866.

[11] ASTM, C170-90, Standards. (1993). Standard test method for compressive strength of dimentionalstrones, 828.

[12] ASTM, C204-82, Standards. (1993), Standard test method for fineness of Portland cement by Air permeability apparatus.

[13] Aïtcin, P. C., Jolicoeur, C., \&MacGregor, J. G. (1994).Concrete International, 16, 45.

[14] Rixom, R., \&Mailvaganam, N. (1999). Chemical Admixtures for Concrete, 3 rd ed, E \& FN Spon. http://dx.doi.org/10.4324/9780203017241.

[15] Yamada, K., Takahashi, T., Hanehara, S., \&Matsuhisa, M. (2000).Cement \& Concrete Research, 30, 197. http://dx.doi.org/10.1016/S00088846(99)00230-6.

[16] Zhang, D.F., Ju, B.Z., Zhang, S.F. \& Yang, J.Z. (2007). J. Appl. Polym. Sci, 105, 486. http://dx.doi.org/10.1002/app.26152

[17] Oroka, I. (1979). Portland cement Paste and Concrete, $1^{\text {st } E d n, ~ M a c k m i l l a n ~ L t d . ~}$

[18] Beeldens, A., Van, G. D., Schorn, H., Ohama, Y., \&Czarnecki, L. (2005). Materials \& Structures, 38, 601. http://dx.doi.org/10.1007/BF02481591.

[19] Lal, R. A., Singh, M. N., \& Das, S. (1986). Met. Org. Chem, 4, 513.

[20] Dong, F. Z., Ben, Z. J., Shu, F. Z., Lu, H., \& Jin Z. Y. (2007).Carbohydrate Polymers, 70 , 363. http://dx.doi.org/10.1016/j.carbpol.2007.04.024.

[21] Kasai, Y., Matsui, I., \& Fukushima, Y. (1982). $3^{\text {rd }}$ Int. Polymers in Concrete, Japan, 1, 172.

[22] Lea, H., \& Neville, K. (1967). Handbook of Epoxy Resins, McGraw Hill, New York.

[23] Negim, S.M., Ayoub,M.M.H., Enany,G.M., Mun, G.A.(2006).Eurasian ChemTech Journal, 8, 243.

[24] Negim, E.S.M, Aisha, A.M.B., Yessimkanova, U., Kurmanbekova, A., Tyazhina, K., Urkimbaeva, P.I., Rakhmetullayeva, R.K., Shatabayeva, E., Irmukhametova, G., Mun, G.A., Yeligbayeva,G.Zh., Khatib, J.M. (2015).International Journal of Basic and Applied Sciences, $4,10$.

[25] El-Sayed, Negim, Latipa,Kozhamzharova,Jamal,Khatib,Lyazzat,Bekbayeva,Craig, Williams. (2014).The Scientific World Journal , 10. 